\title{
Inshallah: Extensive Flouting of Grice's Maxim of Quality
}

\author{
Mohammad Issa Mehawesh ${ }^{1} \&$ Abdullah Ahmad Jaradat ${ }^{2}$ \\ ${ }^{1}$ Department of English Language and Translation, Zarqa University, Zarqa, Jordan \\ ${ }^{2}$ Dept. of English language and Literature, Hashemite University, Zarqa, Jordan \\ Correspondence: Mohammad Issa Mehawesh, Faculty of Arts, Department of English Language and Translation, \\ Zarqa University, PO box 132222, Zarqa 13132, Jordan. Tel: 962-7-9749-2506. E-mail: \\ mohammedissa33@yahoo.com
}

Received: October 29, 2014 Accepted: December 23, 2014 Online Published: January 14, 2015

doi:10.5539/ass.v11n4p319 URL: http://dx.doi.org/10.5539/ass.v11n4p319

\begin{abstract}
The expression inshallah is one of the most common expressions in daily interactions among Jordanians. The paper assumes that the expression has various non-literal meanings besides the literal one which is an invocation to Allah to enable the speaker to achieve a positive or a negative action. The non-literal meanings, on the other hand, are all cases of flouting Grice's maxim of quality, whereby the speaker does not mean what the words literally mean; however, the addressee or the hearer can figure out the message intended by the speaker. The paper has found out that the various non-literal meanings inshallah serves are: irony, which a typical means for flouting the maxim of quality, threatening, wonder, yes/ok, prohibition, and wishing. Moreover, the study has found out that the utterances containing the expression inshallah will not give the same meaning after the removal of inshallah. And this can be considered another major contribution for the paper since it coined a diagnostic for deriving the non-literal meanings of inshallah. (p. 162)
\end{abstract}

Keywords: inshallah, Grice, flouting, maxim, quality, literal vs. non-literal meaning

\section{Introduction}

This paper studies one of the most common expressions among Muslims, who come from various cultural, racial and linguistic backgrounds. The noticeable salience of the expression inshallah 'God willing' is due to Muslims' belief that all their activities and affairs in this life and their destiny in the afterlife are in the hands of Allah. In other words, the salience of the expression among Muslims is solely accounted for in terms of religion; it cannot be attributed to other cultural, racial or social factors.

Actually, the expression inshallah is so common that it has penetrated every aspect of a Muslim's life. It is commonly used in nearly every statement regarding the future. Generally speaking, inshallah is used to express the speaker's hopes and anticipations regarding a future action. However, this paper provides a unique account of the expression. It claims that inshallah can deliver various meanings some of which are not literal and some are not related to the future or the original meaning of the expression. Moreover, the study will provide a diagnostic test that will be used to identify the non-literal meanings of the expression that are in turn considered floutings of the maxim of quality. The study will show that this expression extensively flouts the maxim of quality in particular to provide totally new meanings the expression does not carry or provide literally.

The study is designed as follows. Section two includes the methodology that is applied in the study. It presents the source of the expressions used as well as how they are going to be analyzed. Section three introduces the theoretical background; it briefly presents Grice's cooperative principle as well as the four pillars of the principle i.e. the maxims of quality, quantity, relation and manner. It also clarifies what is meant by observing, flouting and violating the maxims. The review of literature also presents the main studies that have focused on inshallah from a linguistic perspective. The fourth section presents the literal meanings of inshallah, while the last section is the discussion that presents the new non-literal meanings of inshallah which can be viewed as flouting's of the maxim of quality.

\section{Theoretical Background}

Since its emergence in 1975, Grice's cooperative principle has been abundantly researched and applied in various fields and topics. Rundquist (1992), who sought to find a gender-based explanation for flouting the 
maxims, said that men flout the maxims more than women; a finding which proves the opposite of what the common people believe. Brumark (2006) studied cases of non-observance (flouting and violating) to maxims in family dinner table conversations. She discovered that the ages of children may not affect the frequency of non-observance cases committed by the parents. However, she stated that fathers were more likely to use hints for socializing purposes than mothers. Due to its obvious significance to any field related to the various forms of discourse, whether spoken or written, Grice's maxims have been studied in relation to teaching writing as in White (2011), to politics as in Al-Hammadi and Mohammad (2009), to discourse studies as in Pellegrini, Brody and Stoneman (1987) and in drama as in Khosravizadeh and Sedehvandi's (2011) analysis of the violations and the floutings of the maxim of quantity by the main the characters in the Dinner for Schmucks among other studies. However, in order to apply Grice's cooperative principle as well as the four maxim it subsumes, we need to briefly propose them.

The cooperative principle was proposed by Paul Grice (1975) to describe the requirements for a natural piece of language to be understood. The principle as phrased by Grice himself is: 'Make your contribution such as it is required, at the stage at which it occurs, by the accepted purpose or direction of the talk exchange in which you are engaged (p. 47).' Obviously, the principle requires that one make his or her participation in a conversation as required by the situation through the means of communication that are applied in the situation at hand.

The cooperative principle subsumes four maxims that specify the precise requirements on the part of the speaker to be viewed as cooperative. The first maxim is quantity which calls for providing enough information in order to be understood and not to veil some information or to give too much information otherwise the process of comprehensibility will be blocked. The second maxim is that of quality which necessitates that the speaker be truthful by avoiding saying anything for which he or she lacks evidence for or anything they are not sure about. The third maxim is relation which requires that the given information be directly and frankly relevant to the topic of the conversation. The fourth and the final maxim is manner which calls for being clear through being brief, being orderly, avoiding obscurity, and avoiding ambiguity. Grice suggests that the speaker who abides by the four maxims will not face any miscomprehension from the other conversationalist.

However, our speech does not demonstrate all the time that we are observing these maxims while in truth we are. In this case we are flouting the maxims. When flouting a maxim, the speaker is intentionally trying to give a special meaning that is different from the literal meaning realizing that the addressee or the hearer will understand it. The process is taking place intentionally, but with no intention, on the part of the speaker, to deceive the addressee. Therefore, the speaker who flouts the maxims is still cooperative since he or she is trying provide a message that is truthful, enough, relevant and clear; nevertheless the message does not occur at the literal level.

When violating the maxims, the speaker is not cooperative at all. The speaker is purposefully not giving truthful, enough, relevant and clear information. The speaker is trying to cheat or mislead the addressee through giving dishonest, inadequate or abundant, irrelevant and unclear information.

The maxim of quality is significant since it can be flouted in several ways. Cutting (2002) presents some of the ways through which the maxim may be flouted including, saying something that obviously does not represent what the speakers think,

\section{Literature Review}

In this section, studies that have focused on the salience and the significance of religious expressions, in general, and inshallah in specific in everyday conversation will be presented. I can say as a native speaker of Arabic that it is really hard or even impossible to find a conversation in any dialect of Arabic that is void of a significant number of religious expressions. The appearance of religious expressions in daily conversations is taken for granted as a fact that is not negotiable.

Religious expressions are generally expressions that contain the word Allah including: bIsm Illah 'by the name of

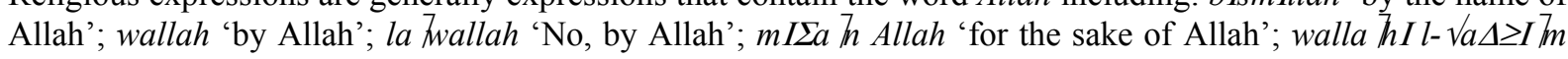
'by Allah, the greatest'; ja Allah 'Oh, Allah'; and inshallah 'if Allah determines so/ God willing'. The salience of these expressions in daily conversations has been emphasized by various scholars including among many Abboud (1988), Gilsenan (1983), and Ferguson (1983). However, specific studies should be mentioned with some details due to their significance. Piamenta $(1979,1983)$ provides the most panoramic collection of Allah expressions in Arabic speech across different dialects. Castleton (2006) surveys Allah expressions in speech as well as other forms of communication. In this context, I find myself obliged to borrow a paragraph by Morrow (2006) illustrating the widespread use of religious expressions: 
The Arabic language is saturated with a rich variety of expressions invoking Allah explicitly or implicitly and ..... the name Allah permeates both spoken and written Arabic to the point where we can speak of the omnipresence of Allah in the Arabic language. As a result, an Arabic speaker could scarcely conceive of a conversation where the name of god would not appear.

Inshallah can be considered one of the most common religious expressions in daily life conversations. In this context Murphy (2006) says:

An American colonel in Iraq, writing to the Washington Post's Thomas E. Ricks, recently observed: ' The phrase 'inshallah' or 'God willing', has permeated all ranks of the Army. When you talk to U.S. soldiers about the possible success of the 'surge', you'd be surprised how many responded with 'inshallah'." The phrase seems to have permeated all ranks of the diplomatic corps, too. Zalmay Kalilzad, when he was the U.S. ambassador to Iraq, once stated at a conference, 'inshallah, Iraq will succeed."

Due to the significance of the expression, it has been abundantly studied. Slackman (2008) describes the extensive use of the expression among Egyptians saying that the Egyptians' frequent use of the expression is 'a signal of their deep faith.' He also adds that recently there has been what he calls 'inshallah creep' since it is attached to any question past, present, or future. Susanto (2006) has studied the role of inshallah in code-switching in Islamic religious discourse saying that the use of the expression by Indonesians in religious gatherings in which only Indonesian is used can be considered as a case of code-switching to gain religious merits. Pishghadam and Kermanshahi (2012) have studied the pragmatic functions of the expression inshallah in Persian. They say that generally speaking, the expression can be used to perform three macro functions with eight micro functions. The macro functions they present are: being a Muslim, dealing with emotions, and showing indirectness. At the end of their study, they compare the linguistic functions of inshallah as used among Persians with the functions of the expression as used among the Arabs, reported by Nazzal (2005). They say that Persians and Arabs seem not to share many similarities. Nazzal (2005) who studies the pragmatic functions of Inshallah among Syrian speakers and who has given just three interactions to support his argument, has restricted the pragmatic functions of the expression to three: the first being used as a mitigating device for rejecting a request; the second being used as a mitigating device of an implicit acceptance; and the third being used as a mitigating device of one's prediction of the future. In addition, he says that the expression can be viewed as a confirmation of one's religious and cultural identity. In other words, I can say that inshallah, according to Nazzal, has two functions: a mitigator and a confirmation of one's identity. However, he does not mention the literal or semantic meaning of the expression on the basis of which the pragmatic meaning was termed so. Cleft and Helani (2010) have reiterated the use of inshallah as a mitigator and added a new pragmatic function: a marker of topic transition. They claim that the appearance of the expression may indicate besides other markers the ending of the topic and the transition to a new one.

Obviously, no previous work has studied the pragmatic meaning of inshallah in Jordanian Arabic, not to mention studying it under the umbrella of the cooperative principle plus its maxims or proposing an analytical device or a diagnostic through which non-literal meanings are distinguished from literal ones.

\section{Methodology}

This study adopts Grice's theory of Cooperative Principle in analyzing the utterances used here. The study claims that the Maxim of Quality, which states that 'a person should not say anything he or she believes to be false or lacks adequate evidence for', is extensively or repeatedly flouted when it comes to the expression inshallah to provide new non-literal meanings. The term 'extensive' is used here to suggest that various meanings for inshallah are obtained as a result of flouting the maxim of quality.

The study will use some actual heard utterances that were collected by the researcher himself as well as some students in the course of Discourse Analysis the researcher teaches at his university. The researcher analyzed the utterances according to the meaning the expression inshallah may carry, and then he offered these meanings to the students who agreed to them.

\section{The Significance of the Study}

With this rich literature about the use of inshallah in daily conversations, an addition to the topic would appear as a challenge that nobody likes to take. However, I have found that inshallah is used in Jordanian Arabic in various meanings that nobody has mentioned before. Moreover, this study is the first that presents a diagnostic that validates that the expression inshallah is in fact the element that carries the new, indirect meanings and is not used as a mitigating expression for the proposition of the statement. Finally, it is the first study that studies inshallah from the perspective of the cooperative principle and its four Maxims. 


\section{Discussion}

This section will present the literal meaning of inshallah providing verses from the Holy Quran as well as examples of actual utterances. In addition, the floutings of the maxim of quality or the non-literal meanings are provided in a separate section. Each non-literal meaning is discussed in details and contains examples to clarify the targeted meanings.

\subsection{The Literal Meanings of Inshallah}

The first thing to mention here is that the use of the expression in conversation is a signal of one's submission to Allah since Allah has decreed in a verse in the Holy Quran that Muslims should not say that they will do anything in the future without saying inshallah. The verse says:

And say not of anything: I will do that tomorrow, unless Allah please. And remember thy Lord when thou forgettest and say: Maybe my Lord will guide me to a nearer course to the right than this. (Surat.18 Al-Kahef, verses $23 \& 24$ )

The verse is in fact a prohibition from Allah that Muslims must not say 'I am going to do this tomorrow' without saying inshallah. Since one cannot be sure whether he or she is going to achieve a certain event in future, they should use this expression as an invocation to Allah to enable them to achieve what they desire. Then, the literal meaning of the expression is an invocation, or a supplication that Allah would make a favorable (sometimes negative) future event occur. In this respect, the mitigating use of the expression, talked about by Nazzal (2005) is closely related to this literal meaning. Consider the following two examples:

1) /In $\Sigma \mathrm{a}\rceil 1 \mathrm{lah}$ bandZa $\square$

If Allah will, I succeed

2) In $\Sigma \mathrm{a}\rceil$ llah ra $\square$ andZa $\square$

If Allah will, I will succeed.

In (1), the speaker is sure about his success; however, he is using inshallah to mitigate his assertiveness abiding by Allah's instructions. This fact is evidenced in his usage of the present tense presenting the future event as a fact. On the other hand, in (2), the speaker is invocating Allah to grant him or her success. Inshallah is used here as an invocation to Allah to enable him to achieve this desired state. Moreover, the speaker is not sure that he would succeed. This is evidenced in using the future marker $r a \square$ and in using inshallah as an invocation to Allah. These two examples show that the mitigating function of inshallah is closely related to the literal meaning of the expression. In addition, the two cases are examples of observing the maxims. The speaker is being clear, saying the truth, telling related information, and giving enough information.

Generally speaking, I can claim that in all the occurrences of inshallah in which the speaker is seriously using the expression in its literal meaning, the expression is observing the maxims. Consider the following example in which inshallah appears alone:

3) wife: bukra badna $\mathrm{nI} \Sigma$ tarI $\Sigma$ waIjIt mala $\rceil$ bIs

Tomorrow we want to buy some clothes

Husband: /In $\Sigma \mathrm{a}\rceil$ llah

If Allah wish/God willing

Wife: /In $\Sigma$ a $\rceil l l a h$

If Allah wish/God willing

In this example, the husband's reply with inshallah observes the maxim of quantity since the expression is taken in itself as a sufficient reply for the wife's suggestion. The husband's reply can be paraphrased as 'if Allah please, we will do that.' The reply also observes the maxim of quality since the husband is telling the truth; he is sincerely wishing that Allah may enable them to buy clothes tomorrow. The expression also observes the maxim of relation since the reply is related to what is said before. The wife is suggesting doing something and the husband is accepting using a conventional expression. Finally, the expression can be said as observing the maxim of manner since the husband is not being ambiguous or slippery. One piece of evidence that can be given here is the emphasis given to the husband's response through the repetition of the expression by the wife. Through this repetition, the wife can be said to agree to what was said by the husband. It seems that the husband is accustomed to saying this expression with a positive meaning, and the wife is accustomed to him saying this expression with this meaning. Consider example (4) which describes a dialogue between an inviter and an 
invitee who are neighbors:

4) inviter: /Iljoum btItfad $\geq$ al tItథada $\sqrt{\text { Indana }}$

You are invited today to have lunch at our house.

Invitee: /In $\Sigma$ a $\rceil l$ lah (bat $\Sigma$ araf)

If Allah wish/God willing (I will be honored to come)

In this example, the invitee's reply is taken as a truthful, sufficient, related and clear acceptance of the invitation. The invitee accepted the invitation through the conventional means to do so in Jordan. This fact is evidenced in the inviter's lack of response; the inviter then asks for permission to leave taking the invitee's reply as an acceptance to the invitation.

These two examples show that as long as the speaker is using the expression inshallah in its literal meaning as an invocation to Allah, the expression can be said to observe the four maxims of the cooperative principle. This is evidenced in the conversationalists' reaction to the expression which reflects their realization of the literal meaning. The following section discuses the non-literal meanings of the expressions which can be seen as floutings of the maxim of quality.

\subsection{Flouting the Maxim}

The expression inshallah has acquired over time a number of non-literal meanings that have become accessible to people as conventionalized meanings. Although these meanings cannot be figured out when the expression is used alone and cannot be found under a dictionary entry of the expression, the expression itself is the source of these new meanings. The diagnostic mentioned previously will be presented here. I term this diagnostic 'isolation and constancy test'. It is based on the idea of whether the remaining elements of the utterance after isolating the expression inshallah would provide the same meaning. In other words, it tests whether the meaning of the utterance will remain constant after isolating or removing inshallah. It has been found that in all the cases, the removal of the expression inshallah will change the meaning or the function of the original utterance. The new meanings of inshallah when used non-literally are given below.

\subsubsection{Irony}

One of the new meanings for inshallah is irony. Inshallah is used to show to the addressee that his or her desired wish under the conditions they both know is simply unreachable or far-fetched. Consider the following example:

5) Student A to student $B$ whose grades are really low

Student A: /In $\Sigma$ a $\rceil l$ lah badIk tIndZa $\square \mathrm{I}$

If Allah please want-you succeed

And you think you're going to pass the course!

Student A is ridiculing student B's wish to succeed. Through this expression, student A is telling B that it is impossible for you to succeed under these conditions. Consider the following example in which the mother is mocking her son's request for a special type of food:

6) son: $\Sigma \mathrm{u}\rceil \otimes$ ada $\rceil k Y$ 1-joum

What do we have for lunch today?

Mother: sabanIx

Spinach

Son: baddI mansaf

I need mansaf

Mother: /In $\Sigma$ a llah hassa bat $\geq$ bYxlak

If Allah please, I'll cook it right now!

The mother is making fun of her son's request to prepare mansaf for him. This meaning is carried out by inshallah and not by the rest of the sentence. The diagnostic applies here: by removing inshallah the meaning of the utterance changes completely. In (5), the utterance becomes a question while in (6) the utterance becomes a promise.

When it comes to observing the maxims, the speaker in the last example has been cooperative through observing three maxims and flouting one. The expression has been understood by the hearers the way it is meant by the 
speaker who observes the maxim of relation since her statement is related to her son's request; the maxim of quantity since her response is taken as sufficient to her son's request and the maxim of manner since her statement was brief, clear and unambiguous. However, the mother's statement flouts the maxim of quality since the she is ironic; she does not really mean that she is going to prepare for him his desired food.

\subsubsection{Threatening}

Inshallah can also be used to express a threatening. In this context, it can be seen as a threatening particle; it is the expression that carries the meaning of a threatening and extends it to an utterance. Without it, the utterance could not be a threatening. The function of the rest of the utterance is to express the content of the threatening i.e. the kind of retribution that may take place in case the warning is not followed. Consider the following example:

7) /In $\Sigma \mathrm{a}\rceil$ llah ba $\Sigma \mathrm{u}\rceil$ fak houn mara Tanjeh, $\otimes$ aIr aksIr rasak

Don't let me see you around here again; I'll break your head

Here the speaker is threatening the addressee not to be seen around or to approach the determined place. Even if we remove the last clause which includes the punishment, the inshallah clause still expresses a threatening. However, when we get rid of the expression inshallah, the remaining clause will not mean a threatening. It may absurdly carry a positive meaning; it is a promise to meet the addressee at that determined place. In the following example, one of the friends is threatening the other of a future consequence in case he did not show up the next day:

8) Friend A: /In $\Sigma \mathrm{a}\rceil$ llah ma $\rceil b t i\rceil d Z I ~ b Y k r a$

Do not dare not to come tomorrow.

This utterance is really significant since it shows that inshallah can be used in negative sentences. Moreover, without inshallah the sentence can be interpreted as a question about whether the addressee is coming tomorrow or not. The two meanings of course depend on intonation. However, with inshallah the utterance is a warning or a threatening of not coming the next day.

When it comes to the conversational maxims, the expression truthfully observes the maxims of quantity as the utterance is taken as sufficient content-wise; relation as the utterance is related to the context or the previous utterance; and manner as the utterance is brief, clear and unambiguous. However, it flouts the maxim of quality as the utterance does not really mean what it literally means. The targeted meaning is different from the surface meaning. Nevertheless, it is accessible to the other conversationalists.

\subsubsection{Wonder}

Inshallah is utilized in this context to express wonder or interjection which may reach the degree of despising or scorning the deed or the event referred to or talked about. Again inshallah is the source of this wonder or scorn. Without it, the sentence could have different meanings. Consider the following examples:

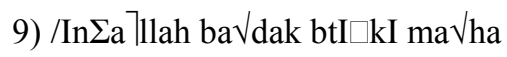

God willing still-you talking with-her

Are you still talking to her!

10) /In $\Sigma$ a $\rceil l$ lah $/ \mathrm{I} \vee$ mIlet hek

God willing did-you so

I hope you didn't do so. (You shouldn't have done so!)

In case inshallah is dropped out from the two examples, the first example would become a question about whether he is still talking to her or not, while the second would become a question about whether he did so or not. Moreover, the expression is followed here by a verb in the past tense since you wonder about or scorn an event that took place in the past.

As in the previous two meanings, the utterance containing the expression observes the maxims of quantity, manner and relation; however, it flouts the maxim of quality due to having a meaning that is different from the literal meaning of the words. The speaker in (9) is not literally wishing that the addressee would not continue talking to her, nor is the speaker in (10) wishing that the addressee did the event referred to.

\subsubsection{Yes/ok}

Inshallah can be used as a positive reply to a yes/no question about a future event or intention. In this context, the expression appears alone without additional words. In the following example, the passenger is asking the 
driver to pull over in order to be able to get off the car; the driver's reply was simply inshallah meaning 'Ok':

11) passenger: $\left.\mathrm{j} \mathrm{I} \sqrt{ } \mathrm{I}\rceil \mathrm{k} / \mathrm{I}-\bigvee_{\mathrm{a}}\right\rceil \mathrm{fj} \mathrm{eh}$

(May Allah)Give-you the-health

Would you please pull over? (Can I get off here?)

Driver: / In $\Sigma \mathrm{a}\rceil$ llah

God willing

Yes/sure/Ok

The driver here is not mitigating his statement since inshallah is the statement itself; and he is not threatening, or being ironic, or wondering about the request made by the passenger since the driver did as he was told. In the following example, the speaker is requesting the addressee to company him to visit the dentist; the addressee in turn responded with inshallah indicating his willingness to do what he was requested to do:

12) A: baddI mInnak tru $\square$ ma $\sqrt{ }$ V Ind dYktor IIsna $\rceil n$

I want from-you go with-me to doctor teeth

'I want you to company me to visit the dentist.'

B: /In $\Sigma \mathrm{a}\rceil$ llah

God willing

'ok/ I will do it.'

In this case, inshallah can be considered as the second part of an adjacency pair expressing a positive response to a request.

Obviously, this meaning of the expression observes the maxim of quantity since the expression is sufficient by itself to perform the function; it observes relation since it is related to the previous request; and observes the maxim of manner as it is brief, clear and unambiguous. Nevertheless, it flouts the maxim of quality since the speaker targeted a meaning that is different from the literal meaning of the expression.

\subsubsection{Prohibition}

Inshallah can be used to express prohibition. A mother can prohibit her son from going out by simply using inshallah followed by a clause expressing the prohibited action. In this sense, inshallah is closer to the meaning of threatening talked about previously since in both cases the expression is followed by a verb in the present form which is the form usually used in regular prohibitions. Nevertheless, the two are different. Inshallah used as a threatening can be followed by an affirmative or a negative verb, while in case of prohibition the expression must be followed by a positive or an affirmative verb since inshallah itself carries the meaning of prohibtion, and performs the same function, of 'Don't'. Compare the same prohibition written twice, one with inshallah and the other with the regular particle for prohibition:

13) A: /In $\Sigma \mathrm{a}\rceil$ llah tIt $\geq \mathrm{la} \sqrt{ }$ mIn Il-beat

Inshallah go out from the-house

Don't go outside the house.

B: la $\rceil$ tIt $\geq$ la $\sqrt{ }$ mIn Il-beat

Don't go out from the-house

Don't go outside the house.

The two examples are identical in all aspects except in the use of inshallah instead of $l a\rceil$ which is the regular particle for prohibition. Furthermore, the meaning of inshallah here is not the literal one that we can find in dictionaries or use in written materials. Obviously, it is inshallah that makes the statement a prohibition; in case it is dropped the statement would become ungrammatical and meaningless. Moreover, another way of proving that the function of inshallah statement is prohibition is by looking at the subject of the two sentences; it is not frankly expressed; however, it is understood as 'you'. In other words, it is the normal subject in imperative sentences. Consider the following two examples:

14) /In $\Sigma \mathrm{a}\rceil$ llah tru $\square \mathrm{I}$ la $\square \mathrm{a}\rceil \mathrm{lIk}$

inshallah go-you alone 
Don't go alone/by yourself.

15) /In $\Sigma \mathrm{a}\rceil$ llah tInsa Eanettak marah Ta \njeh

inshallah forget back bag time second

Don't forget your backbag again.

As said before, the speaker used inshallah in its non-literal meaning in order to perform a function that is easily realized by the addressee as a prohibition. One can say that this new meaning has become conventionalized and accessible to all members of the speech community. The expression observes the maxims of quantity, relation and manner due to being sufficient, relevant, brief, clear and unambiguous. However, it flouts the maxim of quality as the meaning it expresses is different from the literal meaning of the words though being accessible to the addressees. The speaker in each case does not supplicate to Allah to make the addressee able to do any of actions expressed in the sentences. On the contrary, the speaker is warning the addressee not to do these actions.

\subsubsection{Wish}

In this section, I am going to present an argument which is considered against the argument of Nazzal that inshallah is used as a mitigator. Consider the following situations:

16) /In $\Sigma \mathrm{a}\rceil$ llah /andZa $\square$

God's willing I succeed.

I wish I would succeed.

17) /In $\Sigma \mathrm{a}\rceil$ llah /Imu $\rceil \mathrm{t}$

God's willing he dies.

I wish he would die soon.

In each of the following situations, the speaker is not mitigating his wish; rather, he is emphasizing or enhancing the wish by resorting to the omnipresent and omnipotent who is willing to grant a person success or to determine a person's death. In fact, the expression is the source of the wish meaning and the without it the statement would not be a wish anymore; the two sentences would mean 'I succeed' and 'he die' respectively. The remaining parts would be fragments in meaning and structure. Another piece of evidence that inshallah is a wish particle is that it can be replaced with two literal wish particles:

18) ja $7 \mathrm{ra}\rceil \mathrm{t}$

I wish this would happen

19) batmanna

I wish

The speaker could have used these expressions instead of inshallah; however, by doing so the speaker would be accused of ignoring Allah's will. Clearly, the meaning of wishing goes against the meaning of mitigating.

\section{Conclusion}

The study has given an account of the literal and non-literal meanings of one of the most common religious expressions i.e. inshallah in Jordanian Arabic. The paper has suggested that the expression is used in a number of varied unrelated texts to provide some varied non-literal meanings. The study has argued that the expression has a literal meaning i.e. 'supplication to Allah' that observes the cooperative principles and the four maxims, as well as some non-literal meanings that flout the maxims of the cooperative principle. Moreover, the study has shown that the expression itself i.e. inshallah is the source of these new meanings or functions. The evidence from this study has shown that non-literal meanings flout the cooperative principle since they have become conventionalized meanings that are stable in all situations. They are easily-accessible to the addressee who does not require much effort in analyzing them. The context helps the hearer to determine which of the above mentioned meanings is targeted by the speaker. The findings of this study might pave the way for other studies about inshallah that may focus on the prosodic indicators of each meaning the expression may carry.

\section{Acknowledgements}

This research is funded by the Deanship of Research in Zarqa University/Jordan. 


\section{References}

Abboud, P. F. (1988). Speech and religious affiliation in Egypt. In M. A. Jazayery, \& W. Winter (Eds.), Language and Cultures: Studies in honor of Edgar C. Polome (pp. 21-27). Berlin: Mouton de Gruyter. http://dx.doi.org/10.1515/9783110864359.21

Al-Hammadi, H. M., \& Behja, J. M. (2009). Grice's conversational Maxims Violations in the Responses of Western Politicians. Journal of the College of Arab Unversity of Basrah, 50, 1-23.

Ali, A. Y. (n. d.). The Meanings of the Holy Quran.

Archer, D., Aijmer, K., \& Wichmann, A. (2012). Pragmatics: An Advanced resource Book for Students. New York: Routledge.

Brumark, A. (2006). Non-Observance of Grecian Maxims in Family Dinner Table Conversation. Journal of Pragmatics, 38(8), 1206-1238. http://dx.doi.org/10.1016/j.pragma.2005.03.014

Castleton, B. (2006). Frequency and function of religiously-based expressions. In J. A. Morrow (Ed.), Arabic, Islam, and the Allah Lexicon: How language shapes our conception of God (pp. 71-115). Lewiston: The Edwin Mellen Press.

Cleft, R., \& Helani, F. (2010). Inshallah: Religious Invocations in Arabic Topic Transition. Language in Society, 39, 357-382. http://dx.doi.org/10.1017/S0047404510000199

Ferguson, C. A. (1983). God-wishes in Syrian Arabic. Mediterranean Language Review, 1, 65-83.

Gilesnan, M. (2000). Recognizing Islam: Religion and Society in the Modern Arab World. Pantheon.

Grice, H. P. (1975). Logic and Conversation. In P. Cole, \& J. Morgan (Eds.), Syntax and Semantics 3: Speech Acts (pp. 41-55).

Khosravizadeh, P., \& Sedehvandi. (2011). Some instances of Violation and Flouting of the Maxim of Quantity by the Main Characters (Barry and Tim) in Dinner for Schmucks. 2011 International Conference on Language, Literature and Linguistics. LACSIT Press: Singapore.

Morrow, J. A. (Ed.) (2006). Arabic, Islam, and the Allah Lexicon: How language shapes our conception of God. Lewiston: The Edwin Mellen Press.

Murphy, C. (2010). Inshallah. The American Scholar. Autumn issue.

Nazzal, A. (2005). The pragmatic functions of the recitation of Quranic verses by Muslims in their oral genre: The case of inshallah, 'God's willing'. Pragmatics, 15(2/3), 251-273.

Pellegrine, A. D., Brody, G. H., \& Stoneman, Z. (1987). Children's Conversational Competencies with Parents. Discourse Strategies, 10(1), 93-106.

Piamenta, M. (1979). Islam in everyday Arabic Speech. Leiden: E. J. Brill.

Piamenta, M. (1997). The Muslim Conception of God and Human Welfare as reflected in Everyday Arabic Speech. Leiden: E. J. Brill.

Pishghadam, R., \& Kermanshahi, P. N. (2012). Inshallah (God's willing) and its functions in Persian. Studies in Literature and Language, 4(1), 6-11.

Rundquist, S. (1992). Indirectness: A Gender Study of Flouting Grice's Maxims. Journal of Pragmatics, 18(5), 431-449. http://dx.doi.org/10.1016/0378-2166(92)90083-N

Slackman, M. (2008). With a word Egyptians leave it all to fate. New York Times.

Susanto, D. (2006). Code switching in Islamic religious discourse: The role of inshallah. A paper presented to the Second Annual Rhizomes: Re-visioning Boundaries, Conference of the School of Language and Comparative Cultural Studies, The University of Queensland.

White, R. (2001). Adopting Grice's Maxims in the Teaching of Writing. ELT Journal, 55(1), 62-69. http://dx.doi. org/10.1093/elt/55.1.62

\section{Copyrights}

Copyright for this article is retained by the author(s), with first publication rights granted to the journal.

This is an open-access article distributed under the terms and conditions of the Creative Commons Attribution license (http://creativecommons.org/licenses/by/3.0/). 